\title{
Glutathione S-transferases in alcoholic liver disease
}

\author{
D J Harrison, L May, P C Hayes, M M Haque, J D Hayes
}

\begin{abstract}
There is already evidence in alcoholic liver disease, mostly from studies of morphology and cytokeratin distribution, that hepatocytes can undergo a variety of phenotypic changes. This study reports findings of immunohistochemistry using antibodies against members of the glutathione S-transferase supergene family of detoxification enzymes. Hepatocytes in severe alcoholic liver disease coexpressed both alpha and pi class glutathione S-transferase. This coexpression has been previously described only in human fetal liver and in chemically-induced preneoplastic foci in rat liver. The use of function associated markers should provide additional information in the investigation of liver disease.
\end{abstract}

Changes in drug metabolism, and in particular the expression of detoxification enzymes, often accompany liver disease, probably as a consequence of chemical stress. The best known instance is the induction of $\gamma$-glutamyltranspeptidase in alcoholic liver disease. Other enzyme systems may also be involved. For example, in the mouse, chronic feeding with ethanol results in a significant increase in hepatic glutathione S-transferase activity. ${ }^{1}$ These enzymes represent a multigene family of enzymes which catalyse the conjugation of reduced glutathione with many electrophilic substances including drugs, herbicides, and carcinogens..$^{2-5}$ Three classes of cytosolic glutathione S-transferase exist in mammals - these are called alpha, $\mathrm{mu}$, and $\mathrm{pi}^{3}{ }^{3}$ and in man they were previously designated by their isoelectric values as basic, neutral, and acidic type glutathione S-transferase respectively. Each of these classes is distinct as judged by structural and functional criteria; they are believed to be encoded by different clusters of genes. ${ }^{6}$ An additional isoenzyme, which is membrane bound and called microsomal glutathione S-transferase, has recently been isolated from human liver. ${ }^{7}$

The different classes of glutathione $S$ transferase show a noticeable tissue specific expression and although this aspect has not been rigorously studied in man, these enzymes are potentially valuable as immunohistochemical markers.

Quantitatively, the alpha class glutathione S-transferase represents the predominant isoenzyme in adult liver, and this enzyme is present only in hepatocytes and in some cells in large bile ducts. By contrast, pi class glutathione S-transferase is only present in bile ducts. ${ }^{8}$ Little is known about the localisation of $\mathrm{mu}$ class glutathione S-transferase but its expression is variable, being absent in $45 \%$ of human livers. ${ }^{9}$ The distribution of the microsomal glutathione S-transferase in human tissues is unknown. ${ }^{10}$
Another feature of alcoholic liver disease is the acquisition by hepatocytes of a bile duct phenotype, as determined by the pattern of cytokeratin reactivity and the expression of tissue polypeptide antigen. ${ }^{11-13}$ This may be associated with the morphological appearance of 'ductular metaplasia' of hepatocytes.

In this study the expression of glutathione S-transferase isoenzymes in alcoholic liver disease has been undertaken for several reasons. Firstly, to establish whether there is a change in hepatocyte phenotype, as defined by glutathione Stransferase isoenzyme expression. Secondly, to assess immunohistochemically whether differential induction of the various glutathione S-transferase classes is observed in alcoholic liver disease. Thirdly, to investigate whether people who lack mu class glutathione S-transferase are more likely to have developed liver disease.

\section{Materials and methods}

\section{PATIENTS}

Percutaneous needle liver biopsy specimens from 40 patients with a history of alcohol abuse were studied. Specimens showed a spectrum of alcoholic liver disease changes, ranging from steatosis through alcoholic hepatitis with perivenular fibrosis to micronodular cirrhosis.

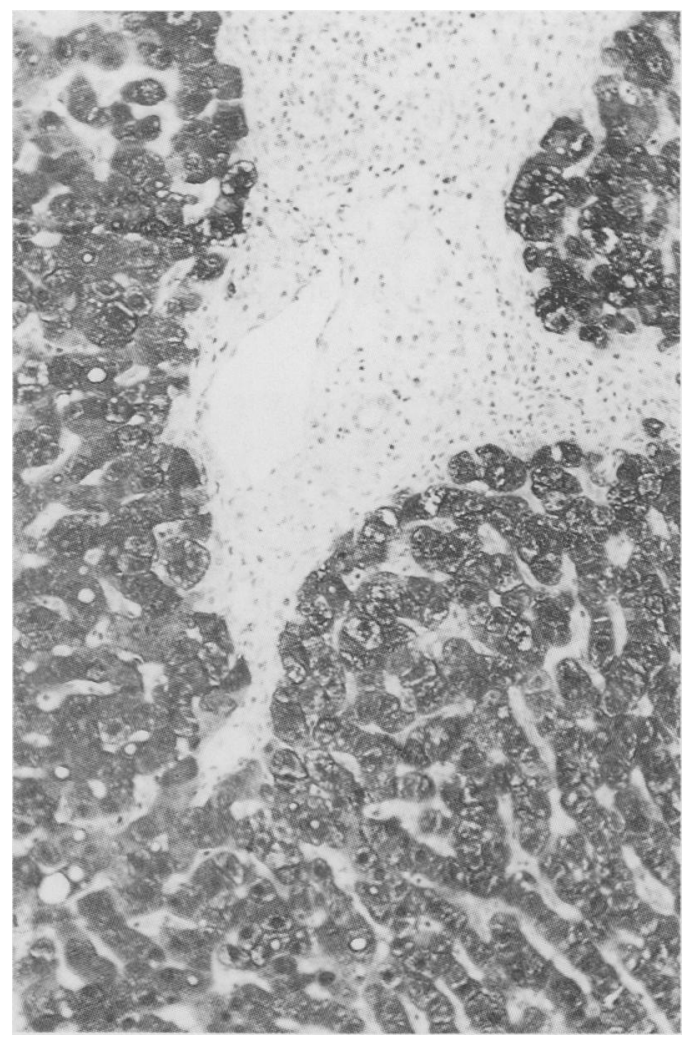

Figure 1: Normal liver stained for alpha class glutathione $S$-transferase. Bile ducts did not stain (original magnification $\times 160)$. 


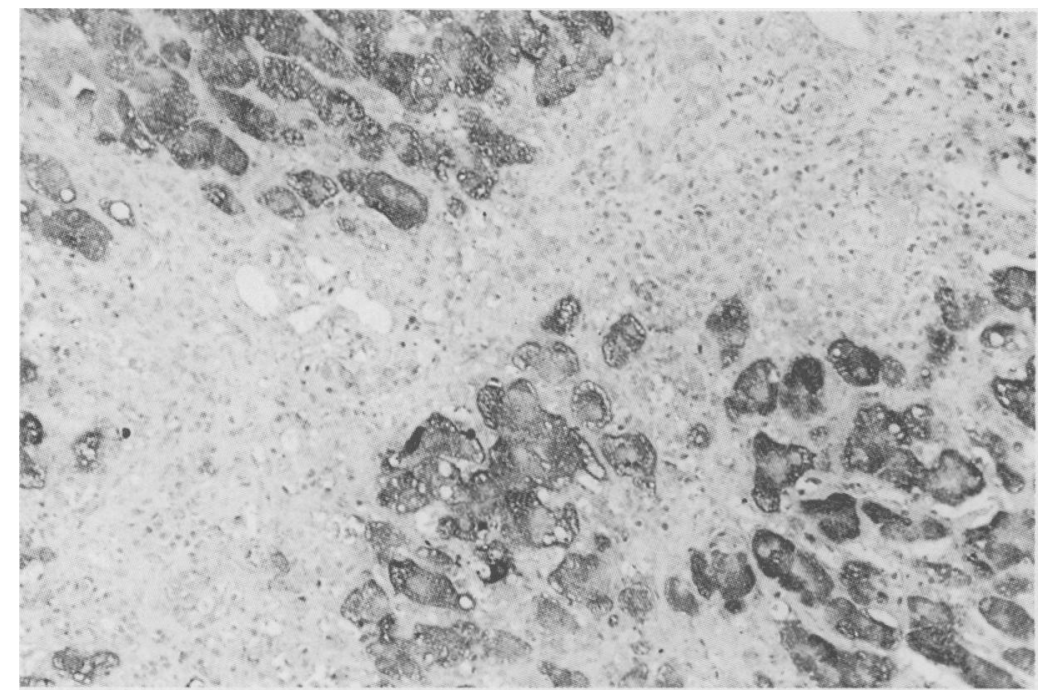

Figure 2: Hepatocytes stained for mu class glutathione S-transferase in cirrhotic liver (original magnification $\times 160$ ).
Expression of pi class glutathione S-transferase (GST) in each morphological group

\begin{tabular}{lccc}
\hline & Bile duct & $\begin{array}{l}\text { Hepatocytes } \\
\text { adjacent to } \\
\text { fibrous tissue }\end{array}$ & $\begin{array}{l}\text { Sinusoidal } \\
\text { cells }\end{array}$ \\
\hline Group & $8^{\star}$ & 2 & 8 \\
\hline Steatosis $(\mathrm{n}=9)$ & 15 & 15 & 10 \\
$\begin{array}{l}\text { Alcoholic hepatitis } \\
\quad \text { and fibrosis }(\mathrm{n}=15)\end{array}$ & 16 & 14 & 4 \\
Cirrhosis $(\mathrm{n}=16)$ & 16 & & \\
\hline
\end{tabular}

$\star$ One specimen did not stain at all for GST pi.

peroxidase with methanol/hydrogen peroxide. Antibody binding was visualised using biotinylated anti-rabbit IgG (Dako) and an avidin-biotin detection system. This is a more sensitive and specific method than that used in our previous study. ${ }^{8}$ Slides were assessed by two independent observers.

\section{Results}

Twenty six of the patients were men and 14 women; their ages ranged from $30-71$ years. Six histologically normal needle biopsy specimens were also studied.

\section{ANTIBODIES AGAINST GLUTATHIONE S- \\ TRANSFERASE}

The cytosolic alpha, mu, and pi class glutathione S-transferases and the microsomal isoenzyme were purified as previously described. ${ }^{67914}$ The polyclonal antibodies that were used in the present study were raised in rabbits and found to be specific as assessed by Western blot analysis. The antibodies against the individual classes of cytosolic and microsomal glutathione S-transferase did not cross-react with any isoenzyme of a different class.

\section{IMMUNOSTAINING}

The method used has been described previously. ${ }^{15}$ Briefly, paraffin sections were dewaxed and incubated with rabbit antibody for one hour at a dilution of 1:200 after blocking endogenous

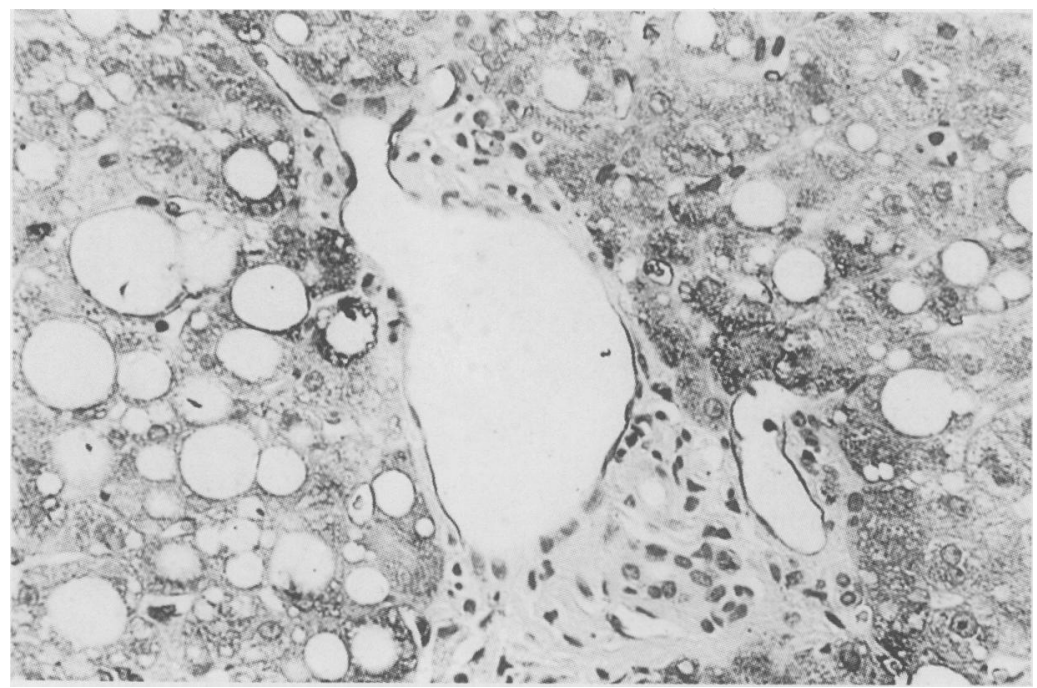

Figure 3: Liver with steatosis stained for microsomal glutathione S-transferase showing endothelial and periportal hepatocyte expression (original magnification $\times 320$ ).

\section{HISTOPATHOLOGY}

Biopsy specimens were divided into three groups according to the nature of the alcohol induced injury. Nine patients showed steatosis with no appreciable fibrosis; 15 patients showed alcoholic hepatitis with varying degrees of pericellular and perivenular fibrosis; and 16 patients showed established micronodular cirrhosis.

\section{IMMUNOHISTOCHEMISTRY}

Alpha class. Each of the normal biopsy specimens showed strong staining of hepatocyte nuclei and cytoplasm (Fig 1). For all patients with alcoholic liver disease, antibodies to alpha

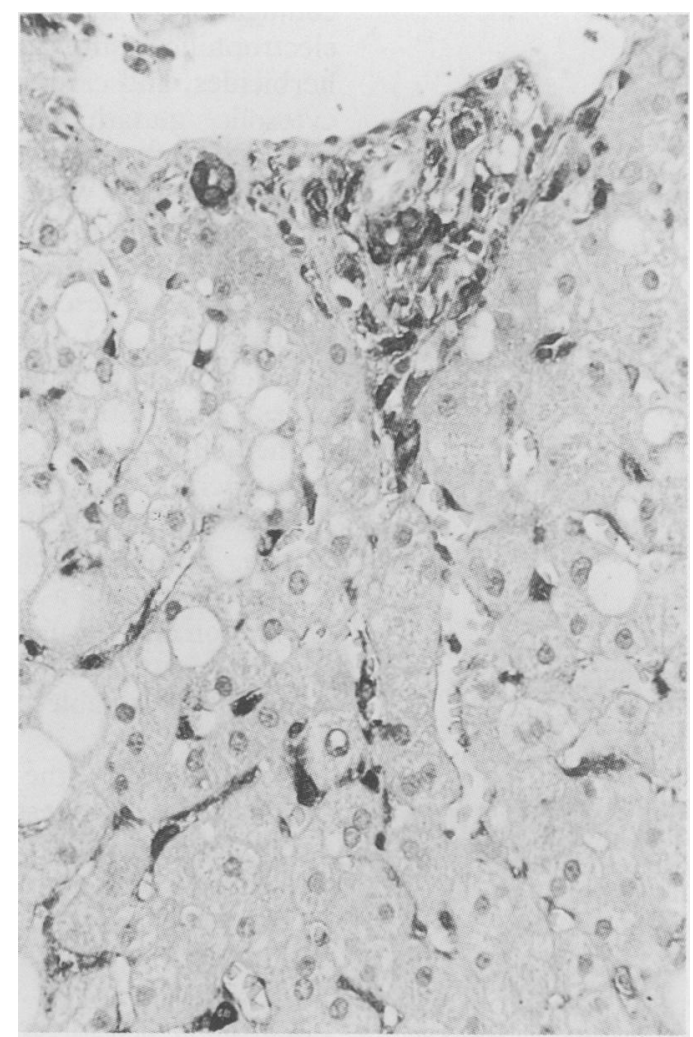

Figure 4: Liver with steatosis showing pi class glutathione $S$-transferase in bile ducts portal tract, inflammatory cells, and sinusoidal lining cells (Kupffer cells) (original magnification $\times 320$ ) 


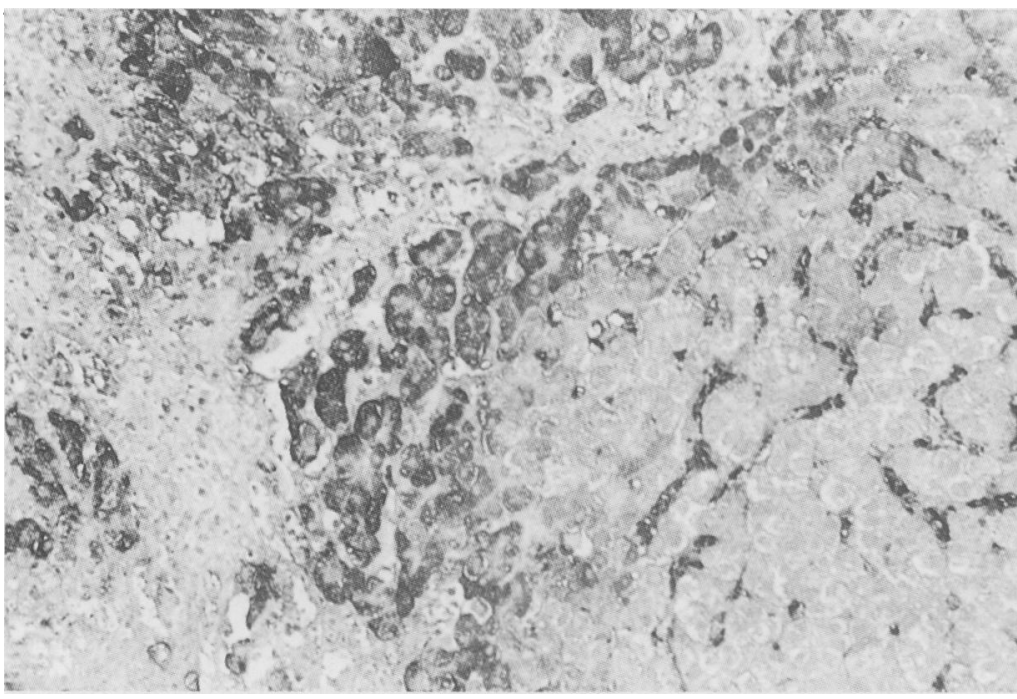

Figure 5: Strong expression of pi class glutathione $S$-transferase in hepatocytes at the edge of a cirrhotic nodule and hepatocytes entrapped within fibrous tissue. Sinusoidal cells are tissue. Sinusoidal cells
also stained (original magnification $\times 160)$.

class glutathione S-transferase showed uniform strong staining of hepatocytes; both cytoplasm and some nuclei. Bile ducts and sinusoidal cells were not stained.

$M u$ class. The anti-mu class glutathione S-transferase antisera gave variable and often weak staining of hepatocytes (Fig 2) similar to that seen in normal liver. ${ }^{8}$ In 14 specimens no definite staining was identifiable - six of nine with steatosis, six of 15 with alcoholic hepatitis and fibrosis, and two of 16 with cirrhosis. The distribution of nulled cases was not significant ( $\mathrm{p}>0 \cdot 1, \chi^{2}$ test).

Microsomal glutathione S-transferase. Normal liver gave weak granular cytoplasmic staining of hepatocytes. Biliary epithelium was not significantly stained. Hepatocyte staining was weak and variable with nine specimens of the 40 studied showing no identifiable staining at all. In seven specimens an increase in periportal staining was observed and endothelial staining was noted (Fig 3).

Piclass. In normal biopsy specimens there was uniform staining of bile ducts but hepatocytes were not stained. Results categorised according to morphological groups of alcoholic liver disease are summarised in the Table. All specimens but one showed bile duct staining (Fig 4). In most patients with steatosis only or alcoholic hepatitis, sinusoidal lining cells (probably Kupffer cells) stained for pi class glutathione S-transferase (Fig 4) but normal sinusoidal lining cells did not express this.

Where there was appreciable fibrosis or cirrhosis, hepatocytes were stained for both alpha and pi class glutathione S-transferases (Fig 5). Mallory's hyaline did not contain detectable amounts of any glutathione S-transferase isoenzyme. In some cirrhotic nodules all hepatocytes were found to express pi class glutathione S-transferase.

\section{Discussion}

In this study we have shown that hepatocytes in alcoholic liver disease may express both alpha and pi glutathione S-transferase. This is of interest as pi class glutathione S-transferase in the adult liver is restricted to bile ducts. ${ }^{816}$ This is consistent with reported changes which occur in the hepatocyte cytoskeleton. ${ }^{11-13}$ Coexpression of glutathione S-transferases pi and alpha is found in fetal human liver before 24 weeks' gestation ${ }^{16}$ and is recognised as a step in the development of drug resistant preneoplastic nodules in chemically induced liver carcinoma in rats. ${ }^{17-19}$

The glutathione S-transferase enzymes have several roles besides that of drug detoxification, which may include nuclear RNA processing ${ }^{20}$ and DNA repair after peroxide injury. ${ }^{21}$ Some of these functions may be compromised during alcoholic liver disease. In the plasma of patients with alcoholic cirrhosis, alpha class glutathione S-transferase activities are often raised, even when transaminases are normal, ${ }^{22}$ indicating chronic injurious stimulus of hepatocytes. This and an associated fall in glutathione available for conjugation reactions, can lead to defective detoxification of drugs such as paracetamol ${ }^{5}$ and a failure of the normal handling of a variety of carcinogens. ${ }^{23}$ This may be relevant to the later development of hepatocellular carcinoma in a small proportion of patients with alcoholinduced cirrhosis.

The results of staining for mu class glutathione S-transferase are consistent with the finding that almost half the normal population fails to express this isoenzyme because of a genetic polymorphism. ${ }^{23}{ }^{24}$ Harada $e t ~ a l^{25}$ have noted that liver biopsy samples from a Japanese population of patients with hepatitis and carcinoma were less likely to express mu class glutathione S-transferase. In our small series there was no statistically significant relation between severity of alcohol injury and mu class glutathione S-transferase status. To detect minor differences in mu expressor status when around half of individuals are nulled would require a very much larger study group. People who lack a glutathione S-transferase with high activity towards trans-stilbene oxide, now known to be a mu class enzyme, have an increased susceptibility to lung cancer. ${ }^{26}$ These people possibly possess a more general susceptibility to chemical insult that may result in a proneness towards developing several types of liver disease.

Our study provides preliminary evidence that microsomal glutathione S-transferase is polymorphic in man. The basis of this and its biological as well as pathological consequences merit further study. We are now undertaking this work.

It is not clear how the de novo expression of pi class glutathione S-transferase in sinusoidal lining cells, presumably Kupffer cells, relates to other studies which have shown a decrease in lysozyme content, phagocytic ability, and absolute number of these cells. ${ }^{2728}$ Activated alveolar macrophages, however, also express glutathione S-transferase pi (unpublished observations). The assessment of hepatocyte differentiation by both cytoskeletal and functional associated phenotypic markets provides a valuable approach to the investigation of the liver's response to injury.

We are grateful to Dr G J Beckett for help in raising antibodies to cytosolic glutathione S-transferase and Dr L I McLellan for providing the antiserum against microsomal glutathione $S$-transferase. This work was supported by Scottish Hospitals Endowment Research Trust grant 961 
1 David RM; Nerland DE. Induction of mouse liver glutathione S-transferase by ethanol. Biochem Pharmacol 1983; 32: 2809-11.

2 Jakoby WB. Glutathione S-transferases: a group of multifunctional detoxification proteins. Adv Enzymol 1977; 47: 383-414.

3 Mannervik B. The isoenzymes of glutathione S-transferases. Adv Enzymol 1985; 57: 357-417.

4 Chasseaud LF. The role of glutathione and glutathione $\mathrm{S}$-transferases in the metabolism of chemical carcinogens S-transferases in the metabolism of chemical carcinogens
and other electrophilic agents. Adv Cancer Res 1979; 29: and other

5 Lauterburg BH, Velez ME. Glutathione deficiency in alcoholics: risk factor for paracetamol hepatotoxicity. Gut 1988; 29: 1153-7.

6 Hayes JD, McLellan LI, Stockman PK, Chalmers J, Beckett GJ. Glutathione S-transferases in man: the relationship between rat and human enzymes. Biochem Soc Trans 1987; 15: 721-5.

7 McLellan LI, Wolf CR, Hayes JD. Human microsomal glutathione S-transferase: its involvement in the conjugation of hexachloro-1, 3-butadiene. Biochem 1989; 258: 87-93.

8 Hayes PC, Harrison DJ, Bouchier IAD, McLellan LI, Hayes JD. Cytosolic and microsomal glutathione S-transferase JD. Cytosolic and microsomal glutathione S-transferase
isoenzymes in normal human liver and intestinal epithelium. Gut 1989; 30: 854-9.

9 Hussey AJ, Stockman PK, Beckett GJ, Hayes JD. Variations in the glutathione S-transferase subunits expressed in human livers. Biochem Biophys Acta 1986; 874: 1-12.

10 Morgenstern R, De Pierre JW. Membrane-bound glutathione transferases. In: Sies H, Ketterer B, eds. Glutathione conjugation - mechanisms and biological significance. London: Academic Press, 1988: 157-74.

11 Ray MB. Distribution patterns of cytokeratin antigen determinants in alcoholic and non-alcoholic liver disease. Human Pathol 1987; 18: 61-6.

12 Van Eyken P, Sciot R, Desmet VJ. A cytokeratin immunohistochemical study of alcoholic liver disease: evidence that hepatocytes can express 'bile duct type' cytokeratins. Histopathology 1988; 13: 605-18.

13 Burt AD, Stewart JA, Aitchison M, MacSween RMN. Expression of tissue polypeptide antigen (TPA) in fetal and adult liver: changes in liver disease. $\mathcal{F}$ Clin Pathol 1987; 40: 719-24.

14 Hayes JD, Mantle TJ. Use of immunoblot techniques to discriminate between the glutathione S-transferase Yf, Yk, $\mathrm{Ya}, \mathrm{Yn}-\mathrm{Yb}$ and $\mathrm{Yc}$ subunits and to study their distribution in extrahepatic tissues. Evidence for three immunochemically distinct groups of transferase in the rat. Biochem $\mathcal{F} 1986 ; 23$ : $779-88$

15 Harrison DJ, Kharbanda R, Cunningham DS, McLellan LI, Hayes JD. Distribution of glutathione S-transferase isoenzymes in human kidney: basis for possible markers of renal injury. $\mathcal{F}$ Clin Pathol 1989; 42: 624-8.

16 Hiley C, Fryer A, Bell J, Hume R, Strange RC. The human glutathione S-transferases. Biochem $\mathcal{F}$ 1988; 254: 255-9.

17 Farber E. Cellular biochemistry of the stepwise development of cancer with chemicals. Cancer Res 1984; 44: 5463-74.

18 Sato K, Satoh K, Hatayama I, et al. Placental glutathione Stransferase as a marker for (pre) neoplastic tissues. In: Mangle TJ, Pickett CB, Hayes JD, eds. Glutathione $S$-transferases and carcinogenesis. London: Taylor and S-transferases and carcin

19 Pitot HC. Hepatic neoplasia: Chemical induction. In: Arias IM, Jakoby WB, Popper H, Schacter D, Shafritz DA, eds The liver: biology and pathobiology. 2nd edition. New York: Raven Press, 1988: 1125-46.

20 Bennett CF, Spector DL, Yeoman LC. Non-histone protein $\mathrm{BA}$ is a glutathione S-transferase localised to interchromatic regions of the cell nucleus. F Cell Biol 1986; 18: 315-33.

21 Ketterer B, Tan KH, Meyer DJ, Coles B. Glutathion transferases: a possible role in the detoxification of DNA and lipid hydroperoxides. In: Mantle TJ, Pickett CB, Hayes JD, eds. Glutathione $S$-transferases and carcinogenesis. London: Taylor and Francis, 1987: 149-63.

22 Beckett GJ, Hayes PC, Hussey AJ, Bouchier IAD, Hayes JD. Plasma glutathione S-transferase measurements in patients with alcoholic cirrhosis. Clin Chim Acta 1987; 169: 85-90.

23 Strange RC, Faulder CG, Davies BA, et al. The human glutathione $\mathrm{S}$-transferases: studies on the tissue distribution and genetic variation of the GST1, GST2 and GST3 isoenzymes. Ann Hum Genet 1984; 48: 11-20.

24 Hussey AJ, Hayes JD, Beckett GJ. The polymorphic expression of neutral glutathione S-transferase in human mononuclear leucocytes as measured by specific radioimmunoassay. Biochem Pharmacol 1987; 36: 4013-5.

25 Harada S, Abei M, Tanaka N, Agarwal DP, Goedde HW. Liver glutathione S-transferase polymorphism in Japanese and its pharmacogenetic importance. Hum Genet 1987; 75: and its

26 Seidegard J, Pero RW, Miller DG, Beattie EJ. A glutathione transferase in human leukocytes as a marker for the suscepttransferase in human leukocytes as a marker for the

27 Liu YK. Phagocytic capacity of the reticuloendethelial system in alcoholics. $\mathcal{F}$ Reticuloendothel Soc 1979; 25: 605-13.

28 Mills LR, Scheuer PJ. Hepatic sinusoidal macrophages in alcoholic liver disease. F Pathol 1985; 147: 127-32. 